\title{
ANÁLISE DOS CONFLITOS POR ÁGUA NO ESPAÇO AGRÁRIO PARAENSE (2013-2016)
}

\author{
Luiz Henrique Almeida Gusmão ${ }^{1}$ \\ Daniel Sombra ${ }^{2}$ \\ Francisco Émerson Vale Costa ${ }^{3}$
}

\section{Resumo}

A gestão das águas é bastante complexa no espaço brasileiro e se torna ainda mais onde esse recurso é abundante, como é o caso da Amazônia brasileira, onde há grande capacidade de geração de energia e grandes empreendimentos sendo realizados. Esse contexto espacial se converte em uma seara de conflitos entre comunidades rurais e agentes atuantes no espaço agrário paraense em particular. Esse artigo privilegia os conflitos por água no espaço agrário paraense. O propósito deste estudo é avaliar a distribuição dos conflitos e da quantidade de famílias envolvidas em confrontos por causa da água nos municípios paraenses. Para validação dos resultados da pesquisa foram utilizados dados da Comissão Pastoral da Terra (CPT) no período entre 2013 e 2016, e através destes foram confeccionados mapas temáticos com o fim de analisar minuciosamente essa situação. A partir dos resultados, constatou-se que as regiões de integração do Xingu e do Tapajós concentram a maioria dos conflitos e das famílias afetadas no espaço agrário por conflitos de água, especialmente em decorrência de usinas hidrelétricas em processo de operação. Segundamente, há destaque para os conflitos por água derivados da atividade da mineração e do agronegócio. Os resultados apontam para a necessidade de uma política de gestão dos recursos hídricos própria a um contexto de abundância de águas.

Palavras-chave: Conflitos por água; Abundância de águas; Espaço agrário; Cartografia; Amazônia Paraense.

\section{ANALYSIS OF THE STATE OF PARÁ AGRARIAN SPACE WATER CONFLICTS (2013-2016)}

\begin{abstract}
Water management is complex in Brazilian space, but it becomes more complex where water is an abundant resource, like in Brazilian Amazon, where there is huge energy power capacity and big undertakes in action. This spatial context becomes a conflict scenario between rural communities and agents that act in agrarian space particularly. This paper focus on water conflict in Pará's agrarian space. The study goal is evaluating water conflict and family involved in water conflicts quantity distribution in Pará's municipalities. To valid research outcomes, we used data from Comissão Pastoral da Terra (CPT), in the period 2013-2016, and

\footnotetext{
1 Mestrando em Desenvolvimento e Meio Ambiente Urbano (UNAMA). Graduação em Geografia (2009) na Universidade Federal do Pará (UFPA). Email:

${ }^{2}$ Mestre em Geografia pelo Programa de Pós-Graduação em Geografia da Universidade Federal Fluminense (POSGEO/UFF). Doutorando em Geografia pelo Programa de Pós-Graduação em Geografia da Universidade Federal do Pará (PPGEO/UFPA).

${ }^{3}$ Mestrado em Gestão dos Recursos Naturais e Meio Ambiente pelo Programa de Pós-Graduação em Geografia PPGEO/UFPA (2011) e Doutorado em Geografia pela Universidade Estadual Paulista UNESP/Campus de Presidente Prudente/SP (2017).
} 
trough that we made thematic maps aiming to analyze situation. With the outcomes, in one hand, we realized that Region of Integration of Xingu and Tapajós concentrate most part of the agrarian space water conflicts and affected families, especially because fully operation hydroelectric dams. In other hand, we highlight water conflicts provoked by mining and agribusiness. Outcomes show to the need for a water management appropriated to water abundance contexts.

Key words: Water conflict; Water abundance; Agrarian space; Cartography; Pará's Amazon.

\section{INTRODUÇÃO}

A água é um recurso indispensável à sobrevivência humana, estando presente em vários aspectos da civilização, desde a necessidade fisiológica dos seres humanos até as atividades econômicas como a agricultura, pecuária, geração de energia, indústria, dentre outros.

No Brasil, após a promulgação da Lei no 9.433/1997, que institui a Política Nacional dos Recursos Hídricos houve grandes avanços na gestão dos recursos hídricos, sobretudo no que tange à criação dos Comitês de Bacias Hidrográficas $(\mathrm{CBH})$, mas esse avanço está restrito basicamente às regiões Sudeste e Nordeste do Brasil (COSTA, 2011). Até 2017 só existia um Comitê de Bacia Hidrográfica na Amazônia Legal, o CBH do Rio Tarumã, no Amazonas, criado 2009. Isso não significa que a Amazônia não apresente problemas no que tange aos recursos hídricos, sobretudo na dimensão dos usos competitivos por água (COSTA, 2017), contrastando usos econômicos e sociais da água, que, em determinadas ocasiões, materializam um conflito por água (COSTA et al., 2015).

Para Canto et al. (2015), o conflito pode ser considerado como externalidade, como anomalia, e, numa perspectiva durkheimiana, parte-se do princípio que qualquer grupo social tende à busca de harmonia e equilíbrio. Assim sendo, se a harmonia e o equilíbrio fazem parte do estado "normal" do grupo social, o conflito se manifesta como perturbação, cuja motivação deve ser encontrada fora da "normalidade" do grupo social onde o conflito se manifesta, sendo gerado por externalidades.

Conforme os dados da Comissão Pastoral da Terra (CPT), entre 2007 e 2016 no Brasil, o número de conflitos no campo por água chegou a 939 e o de famílias envolvidas a 356.111, no qual o ápice de maior instabilidade foi o ano de 2016. Entre os estados brasileiros, o Pará destacou-se negativamente como o quarto mais violento no campo com catorze conflitos, porém como o primeiro com relação ao número de famílias envolvidas em confrontos (CPT, 2016).

Nesse contexto, o referido estudo busca analisar a distribuição e as circunstâncias dos conflitos por água no espaço agrário do estado do Pará, com o recorte temporal no período de 
2013 a 2016, com base nas informações disponíveis pela Comissão Pastoral da Terra (CPT) que nos permitiram compilar os dados para a elaboração de mapas temáticos. A partir deles, pode-se discutir criticamente acerca da distribuição dos conflitos e das famílias envolvidas nesses eventos.

\section{MATERIAL E MÉTODO}

O Estado do Pará constitui a segunda maior unidade federativa do Brasil, localizado na Região Norte do país, fazendo limite com os estados do Amapá, Roraima, Amazonas, Tocantins, Mato Grosso e Maranhão. O Pará é constituído por 144 municípios e tem uma população de aproximadamente 7,58 milhões (IBGE, 2010), inserido nas bacias hidrográficas do Amazonas, Atlântico Norte-Nordeste e do Tocantins (CNRH, 2003).

De acordo com a regionalização oficial do Governo do Estado do Pará (2008), o território estadual é dividido em doze regiões de integração (RI) que baseiam as políticas públicas a nível estadual: $a$ ) RI Metropolitana ou Guajará; $b$ ) RI do Guamá; $c$ ) RI do Rio Caeté; d) RI do Rio Capim; e) RI do Baixo Tocantins; $f$ ) RI do Lago de Tucuruí; $g$ ) RI de Carajás; $h$ ) RI do Araguaia; $i$ ) RI do Xingu; $j$ ) RI do Baixo Amazonas; $k$ ) RI do Tapajós; $l$ ) RI do Marajó (Figura 1).

Primeiramente, foi acessado o portal eletrônico da Comissão Pastoral da Terra (CPT) onde foram obtidas as informações referentes aos conflitos no campo por causa da água de todos os municípios do Pará entre o período de 2013 e 2016. Entre os dados disponíveis, foram privilegiados os seguintes: o município de ocorrência, o nome do local, a quantidade de famílias envolvidas nos confrontos e o tipo de conflito por água, todos até a conclusão da lista no final do respectivo ano. Com vista à análise espacial dos acontecimentos relacionados aos conflitos, os dados foram coletados e organizados em uma planilha eletrônica, sendo possível filtrar e analisar as informações mais pertinentes para esta pesquisa, agregando-as posteriormente em um Sistema de Informação Geográfica (SIG).

Para a confecção dos mapas temáticos foram usados os seguintes dados: Quantidade de conflitos por água nos estados brasileiros em 2016; Quantidade de famílias envolvidas em conflitos por água nos municípios paraenses entre 2013-2016 e quantidade de conflitos por água no espaço agrário dos municípios paraenses entre 2013-2016. Todos os mapas temáticos sobre conflitos pela água foram elaborados com o uso das ferramentas de mapeamento do software ArcGis 10.1 através das abordagens: quantitativa, qualitativo e ordinal, propostas por Martinelli 
(2011) e especificadas por Castro et al. (2015). Nos mapas, utilizou-se o sistema de coordenadas geográficas e o datum de referência SIRGAS-2000.

Figura 1: Mapa das regiões de integração do Estado do Pará com as áreas urbanizadas e não urbanizadas

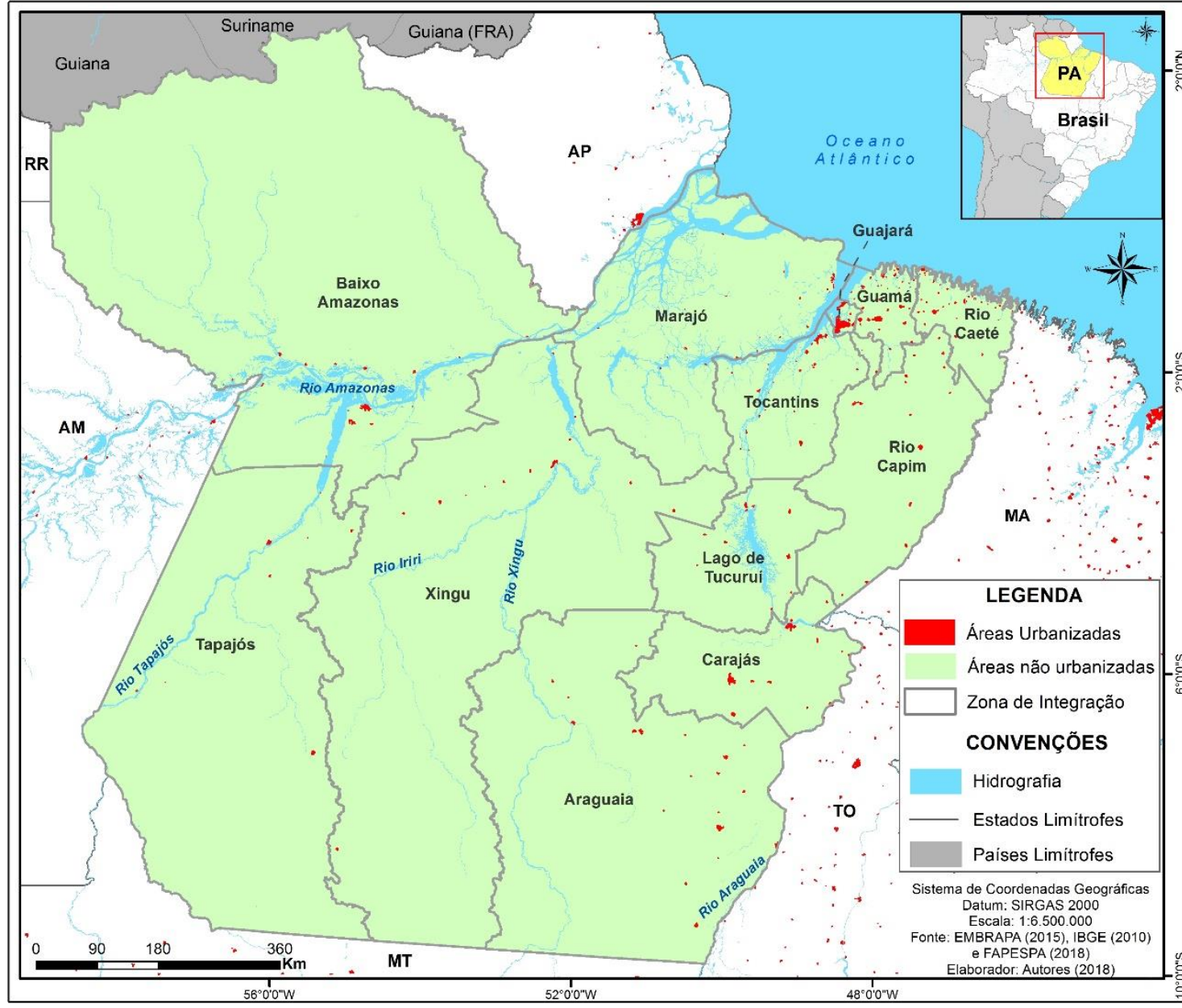

Fonte: EMBRAPA (2015), IBGE (2010) e FAPESPA (2018). Elaboração própria.

Os métodos de mapeamento utilizados nos mapas foram: símbolos proporcionais, coroplético e monocromático (MARTINELLI, 2011), com vista na melhor compreensão da distribuição geográfica. Os conflitos que se estenderam em mais de um município foram registrados nos mapas, porém separados como únicos, não sendo computados no total dos municípios, mas sim como "limites entre os municípios". 


\section{RESULTADOS E DISCUSSÕES}

\section{Análise dos conflitos no campo por água no Estado do Pará}

O Brasil é um país privilegiado em termos de disponibilidade hídrica, abrigando $12 \%$ das reservas mundiais de água doce do mundo, porém apresenta situações contrastantes em relação à abundância e escassez desse recurso, o que exige dos governos, dos usuários e da sociedade civil, melhor organização e planejamento na gestão de sua utilização (MMA, 2006).

Dentre as regiões hidrográficas brasileiras, a Amazônica é sem dúvida, a maior e uma das mais importantes delas, por abranger $40 \%$ do território brasileiro e corresponder a mais de $60 \%$ de toda a disponibilidade hídrica do país (MMA, 2006). Apesar da riqueza hídrica presente na Amazônia, muitos problemas de origem antrópica interferem nos regimes dos rios ou no acesso à água, tais como a mineração, o agronegócio, a urbanização acelerada, entre outras formas de apropriação da terra sem planejamento adequado (BORDALO, 2017).

Paradoxalmente, a Amazônia apresenta um número bastante reduzido de comitês de bacias hidrográficas (COSTA, 2011), bem como ações mal sucedidas com relação à gestão dos recursos hídricos. Costa (2017) aponta que nem mesmo as empresas públicas, como a Companhia de Saneamento do Pará (COSANPA) possui outorga de captação de água superficial ou subterrânea, nem para lançamento de efluentes que pratica na bacia hidrográfica do Rio Caeté. Para Costa (2017, p. 303):

\footnotetext{
"o modelo atual de gestão dos recursos hídricos preconizado pela Política Nacional de Recursos Hídricos e pela Política Estadual de Recursos Hídricos, fundamentadas na delimitação de Bacia Hidrográfica tendo a água como elemento norteador não tem sido eficiente para a implementação efetiva do gerenciamento dos recursos hídricos no Estado do Pará, o que se reflete na bacia hidrográfica do rio Caeté”.
}

Faz-se necessário, para o autor, propor um modelo de gestão mais abrangente, pensando na inter-relação dos elementos e com rebatimento diretos no uso do solo para se fazer a gestão de águas em contextos espaciais de abundância.

Para Campos e Fracalanza (2010, p. 375): “a distribuição da água no território, a forma de ocupação do mesmo pelas populações e a apropriação e consumo desiguais dos recursos hídricos entre os diferentes grupos sociais resultam em conflitos pelos usos da água". No Brasil, os conflitos por água no campo foram mais frequentes nas regiões Sudeste e Nordeste, porém o número de famílias atingidas foi mais representativo nas regiões Norte e Sudeste (Tabela 1). 
Tabela 1: Total de conflitos, famílias e proporção de famílias por conflito envolvidas por água no campo nas regiões brasileiras (2016)

\begin{tabular}{cccc}
\hline REGIÃO & CONFLITOS & FAMÍLIAS & FAMÍLIAS POR CONFLITO \\
\hline Norte & 29 & 17.108 & 590 \\
Nordeste & 42 & 47.451 & 177 \\
Centro-Oeste & 16 & 2.249 & 141 \\
Sudeste & 80 & 15.120 & 189 \\
Sul & 5 & 2.543 & 509 \\
\hline \multicolumn{4}{c}{ Fonte: CPT (2016); Elaboração própria }
\end{tabular}

Entre os estados brasileiros com maior quantidade de conflitos, destacaram-se: Minas Gerais (58), Bahia (24), Espírito Santo (17) e Pará (14), totalizando 65,7\% dos 172 conflitos ocorridos no Brasil, enquanto cinco estados e mais o Distrito Federal não registraram nenhuma ocorrência (CPT, 2016). Já entre aqueles com maior quantidade de famílias envolvidas, o Pará se destacou negativamente com 9.182, seguido pelo Rio de Janeiro (8.096), Rondônia (7.622), Minas Gerais (4.238) e Bahia (3.851), conforme o mapa a seguir (Figura 2).

No outro extremo, alguns estados da região Nordeste não registraram nenhum conflito, assim como Mato Grosso do Sul e Roraima. Por outro lado, os estados do Paraná, Rio Grande do Sul, Goiás, Maranhão e Rio Grande do Norte registraram poucos conflitos, porém o número de famílias envolvidas em confrontos foi alto, acima de 1.000, mas não comparável a Rondônia e Rio de Janeiro, onde o total foi respectivamente de 7.622 e 8.096, o que revela a gravidade desses eventos.

No que se refere ao Pará, este registrou a quarta maior frequência de conflitos por água no Brasil e a maior quantidade de famílias envolvidas nesses eventos no último ano do levantamento (CPT, 2016). Durante o período entre 2013 e 2016, o número de conflitos foi de 58 e 38.482 famílias estiveram envolvidas (CPT, 2013, 2016). 
Figura 2: Mapa com total de conflitos por água no campo e de famílias envolvidas no Brasil (2016)

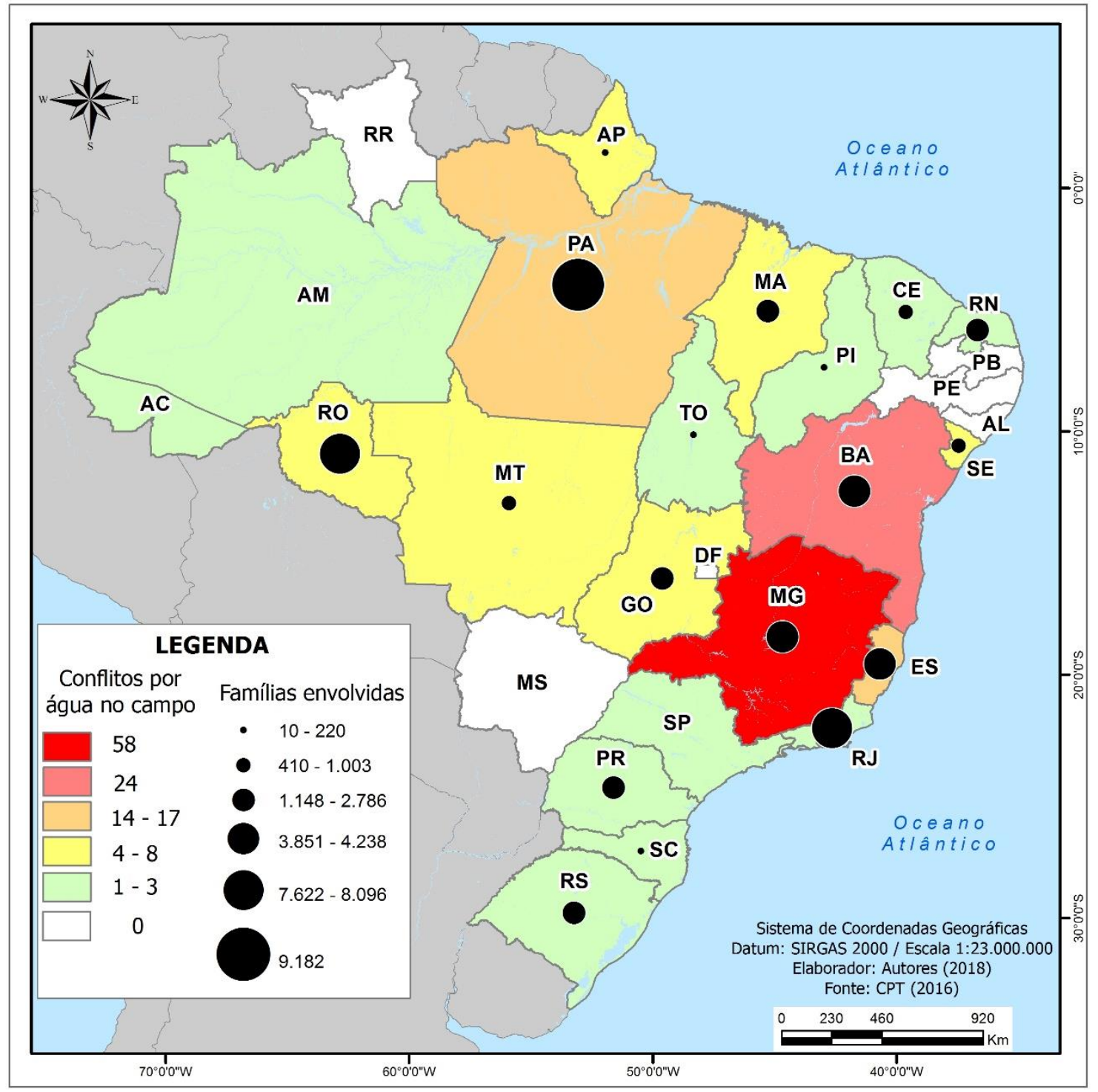

Fonte: CPT (2016); Elaboração própria

Destes, 46 foram relacionados a barragens e açudes (77,9\%), seguido por dez conflitos em decorrência do uso e preservação dos recursos hídricos $(16,9 \%)$ e dois por apropriação particular $(3,2 \%)$, ou seja, a maioria dos confrontos estão relacionados a projetos hidroelétricos. $\mathrm{Na}$ análise realizada por ano, em todos predominam os conflitos por barragens e açudes, tendo diminuído de 15 em 2013 para 9 em 2016, enquanto por uso e preservação dos recursos hídricos saltou de um para quatro no mesmo período (Gráfico 1). 
Gráfico 1: Quantidade e tipo de conflitos por água no espaço agrário paraense (20132016)

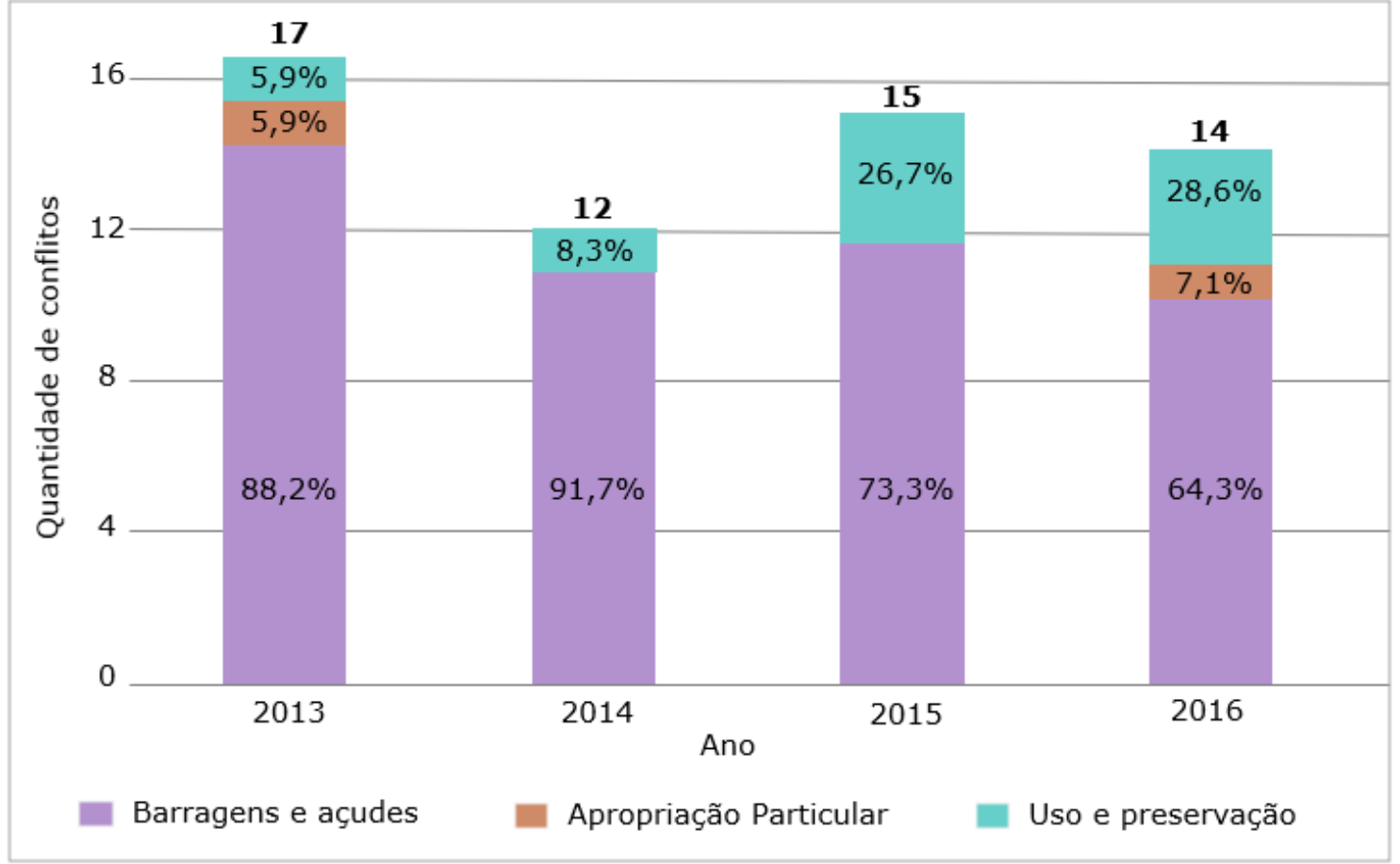

Fonte: CPT (2013-2016); Elaboração própria

Quando avaliada a distribuição geográfica dos conflitos por água no espaço agrário paraense, percebe-se que esta é bastante desigual no território paraense, destacando-se os municípios de Altamira com 14 casos (23,7\%), Senador José Porfírio com 5 casos (8,5\%), a região limítrofe entre Anapu, Senador José Porfírio e Vitória do Xingu com 5 casos $(8,5 \%)$, assim como Barcarena também com 5 casos $(8,5 \%)$, conforme o mapa abaixo: 
Figura 3: Mapa da distribuição dos conflitos por água no campo do Estado do Pará (2013-2016)

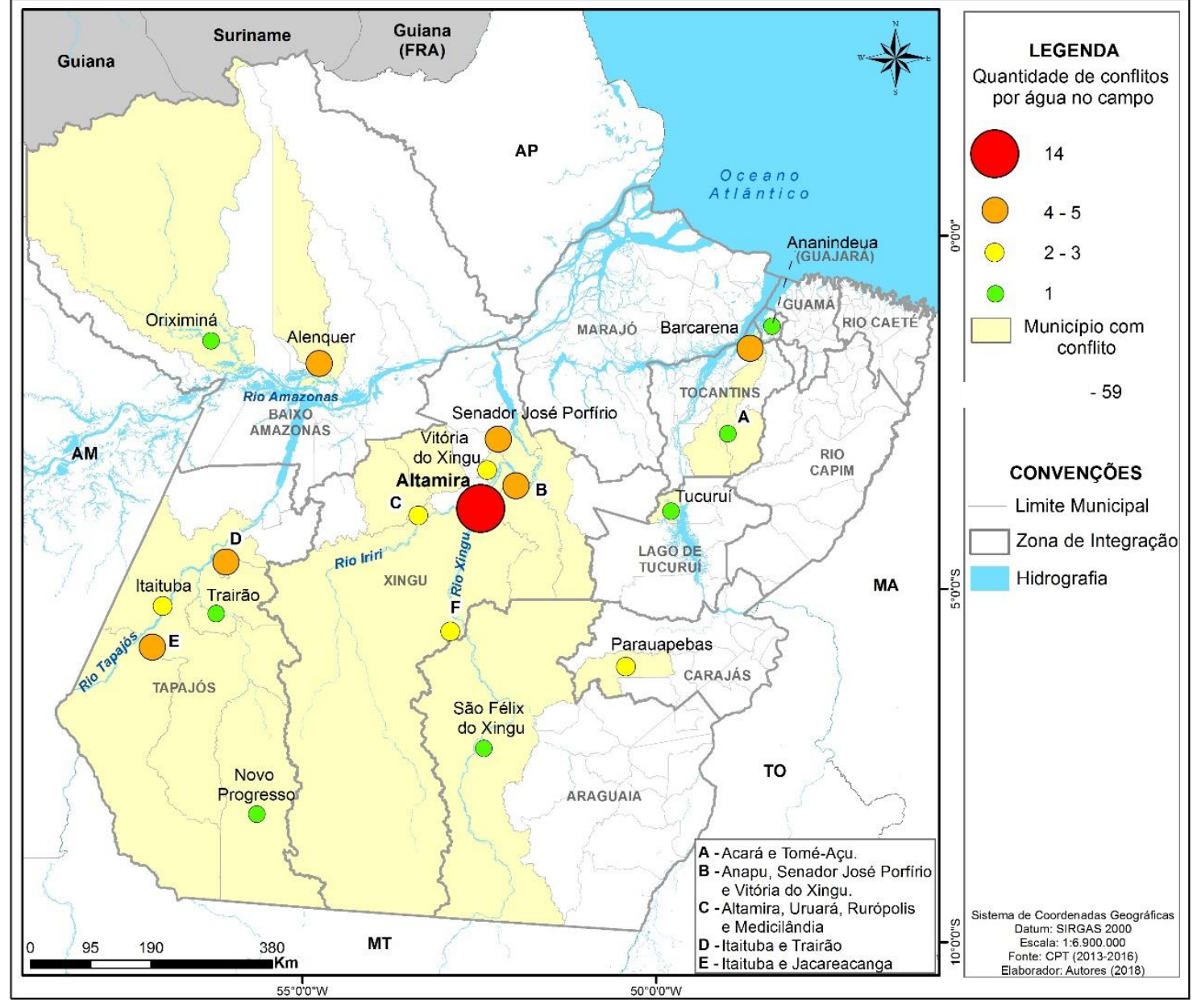

Fonte: CPT (2013-2016); Elaboração própria

Conforme consta no mapa, é visível a concentração de conflitos por água nos municípios da porção sudoeste do Estado do Pará, especialmente na RI Xingu com 28 ocorrências (47,5\%) e na RI Tapajós com 13 casos (22\%), seguido pela RI Baixo Tocantins com 6 ocorrências $(10,2 \%)$, enquanto as demais RI totalizaram $20,3 \%$.

Ainda conforme o mapa, a maioria dos municípios paraenses com maior incidência de conflitos por causa de água no campo estão as margens do rio Xingu e do rio Tapajós, em detrimento de algumas RI da porção Leste, onde os casos de conflitos foram extremamente baixos ou ausente (Tabela 2). 
Tabela 2: Total de famílias e municípios envolvidos em conflitos por causa de água no espaço agrário paraense por Região de Integração (2013-2016)

\begin{tabular}{ccccccc}
\hline $\begin{array}{c}\text { REGIÃO DE } \\
\text { INTEGRAÇÃO }\end{array}$ & CONFLITOS & $\begin{array}{c}\% \text { DE } \\
\text { CONFLITOS }\end{array}$ & FAMÍLIAS & $\begin{array}{c}\% \text { DE } \\
\text { FAMÍLIAS }\end{array}$ & $\begin{array}{c}\text { MUNICÍPIOS COM } \\
\text { CONFLITO }\end{array}$ & $\begin{array}{c}\text { TOTAL DE } \\
\text { MUNICÍPIOS }\end{array}$ \\
\hline Xingu & 27 & 46,6 & 27.686 & 71,9 & 6 & 10 \\
Tapajós & 13 & 22,4 & 7.840 & 20,4 & 4 & 6 \\
Tocantins & 6 & 10,3 & 840 & 2,2 & 2 & 11 \\
Baixo Amazonas & 5 & 8,6 & 1.170 & 3,0 & 2 & 13 \\
Carajás & 2 & 3,4 & 500 & 1,3 & 1 & 12 \\
Xingu-Araguaia & 2 & 3,4 & - & - & 2 & - \\
Lago do Tucuruí & 1 & 1,7 & - & - & 1 & 7 \\
Guajará & 1 & 1,7 & 300 & 0,8 & 1 & 5 \\
Araguaia & 1 & 1,7 & 146 & 0,4 & 1 & 18 \\
Guamá & 0 & 0 & 0 & 0 & 0 & 16 \\
Marajó & 0 & 0 & 0 & 0 & 0 & 15 \\
Rio Caeté & 0 & 0 & 0 & 0 & 0 & 16 \\
Rio Capim & 0 & 0 & 0 & 0 & 0 & 144 \\
\hline Estado do Pará & 58 & 100 & 38.482 & 100 & 19 & \\
\hline
\end{tabular}

Obs: Foram registrados conflitos por água em dois municípios em regiões de integração diferentes "Xingu-Araguaia" Fonte: CPT (2013-2016); Elaboração própria

Quando avaliamos as RI, é interessante perceber que muitas delas, embora com abundância de recursos hídricos e grande população rural não registraram confrontos nesse período, tais como: Marajó, Capim, Caeté e Guamá. Já outras como: Guajará, Araguaia, Carajás e Lago de Tucuruí, ocorreram poucos registros. No geral, mais da metade das RI e 13,2\% dos municípios paraenses já tiveram confrontos em decorrência da água.

Entre as bacias hidrográficas que cobrem o território paraense, a Amazônica concentra o total de conflitos e de famílias diretamente afetadas, seguida pela bacia Atlântico NorteNordeste e bacia do Tocantins, o que ressalta a importância política de preservação dos recursos hídricos e de amenização dessa situação.

$\mathrm{Na}$ análise da frequência de conflitos no período da pesquisa, nota-se que o município de Altamira teve problemas em todos os anos com pico em 2016; Senador José Porfírio e Barcarena nos últimos três anos; Alenquer, a fronteira Acará/Tomé-Açu e o município de Novo Progresso somente em 2013; ao passo que os demais municípios e fronteiras houve alternância de ano dos conflitos (Tabela 3 ). 
Tabela 3: Quantidade de conflitos por água no espaço agrário paraense por município (2013-2016)

\begin{tabular}{|c|c|c|c|c|c|}
\hline \multirow{2}{*}{$\begin{array}{l}\text { MUNICÍPIO OU } \\
\text { FRONTEIRA }\end{array}$} & \multicolumn{5}{|c|}{ CONFLITOS POR ANO } \\
\hline & 2013 & 2014 & 2015 & 2016 & TOTAL \\
\hline Altamira & 3 & 3 & 3 & 5 & 14 \\
\hline Senador José Porfírio & 0 & 1 & 3 & 1 & 5 \\
\hline Barcarena & 0 & 1 & 2 & 2 & 5 \\
\hline Anapu/Senador J. Porf. e Vitória do Xingu & 2 & 0 & 0 & 2 & 4 \\
\hline Itaituba/Trairão & 1 & 1 & 2 & 0 & 4 \\
\hline Itaituba/Jacareacanga & 2 & 1 & 1 & 0 & 4 \\
\hline Parauapebas & 0 & 0 & 1 & 1 & 2 \\
\hline Itaituba & 0 & 2 & 1 & 0 & 3 \\
\hline Uruará/Altamira/Rurópolis e Medicilândia & 1 & 1 & 0 & 0 & 2 \\
\hline Altamira/ São Félix do Xingu & 1 & 1 & 0 & 0 & 2 \\
\hline Vitória do Xingu & 1 & 1 & 0 & 0 & 2 \\
\hline Oriximiná & 0 & 0 & 0 & 1 & 1 \\
\hline São Félix do Xingu & 0 & 0 & 0 & 1 & 1 \\
\hline Tucuruí & 0 & 0 & 0 & 1 & 1 \\
\hline Trairão & 0 & 0 & 1 & 0 & 1 \\
\hline Ananindeua & 0 & 0 & 1 & 0 & 1 \\
\hline Alenquer & 4 & 0 & 0 & 0 & 4 \\
\hline Acará/Tomé-Açu & 1 & 0 & 0 & 0 & 1 \\
\hline Novo Progresso & 1 & 0 & 0 & 0 & 1 \\
\hline Estado do Pará & 17 & 12 & 15 & 14 & 58 \\
\hline
\end{tabular}

Fonte: CPT (2013-2016); Elaboração própria

Em relação ao montante de famílias envolvidas nos conflitos por água no Pará nesse período, é possível afirmar que milhares de pessoas foram afetados anualmente por terem o direito constitucionalmente previsto de acesso à água negado por distintos motivos. Entre 2013 e 2016, houve um aumento de $57 \%$ no número de famílias atingidas por conflitos no Estado do Pará, todavia entre 2015 e 2016, o número reduziu 22,7\%, o que pode revelar uma possível tendência de redução após sucessivos crescimentos (Gráfico 2).

Grande parte das famílias envolvidas em conflitos por água no espaço agrário paraense está nessa situação em virtude da construção de barragens e açudes, sendo necessário, portanto, adotar medidas mitigadoras a fim de não só reduzir o número de pessoas atingidas, mas também minimizar possíveis efeitos nocivos do ponto de vista ambiental, conforme Juchem (1992) apud ELETROBRÁS (1996), tais como: solos e a capacidade de uso das terras; recursos hídricos; uso atual dos solos; a vegetação; a fauna e flora; a geologia e geomorfologia local e as condições climáticas. 
Gráfico 2: Número de famílias envolvidas em conflitos por água no espaço agrário paraense (2013-2016)

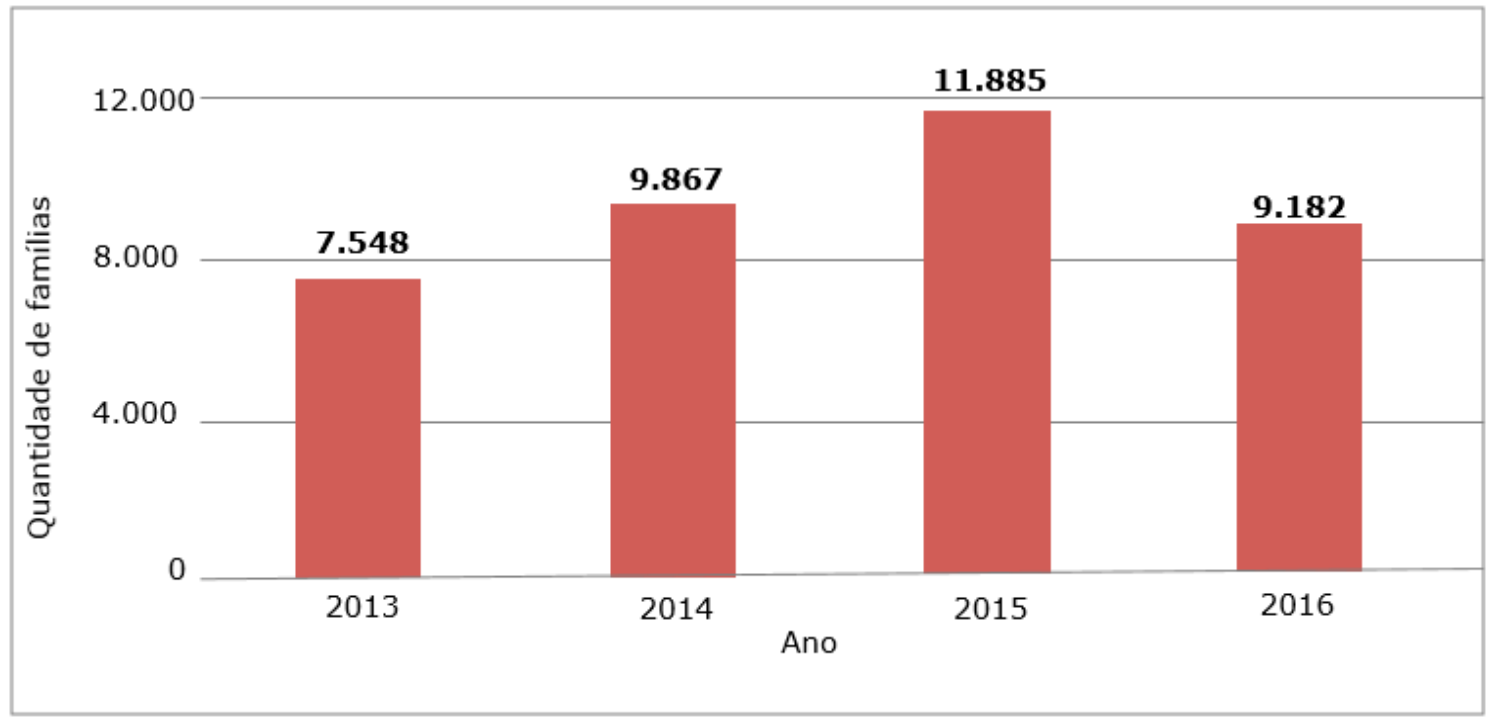

Fonte: CPT (2013-2016); Elaboração própria

Vários impactos são previstos durante a construção de hidrelétricas, especialmente quando estas possuem grandes proporções e localizadas em áreas com rica biodiversidade. Em relação aos fatores socioeconômicos, Juchem (1992) apud ELETROBRÁS (1996) também citam possíveis consequências na (os): situação demográfica rural e urbana; aspectos sociais e culturais; populações indígenas; infraestrutura regional; atividades econômicas; saúde pública; setores de educação, lazer e recreação e sobre o patrimônio cultural, histórico, arqueológico e paisagístico.

Segundo DIAS et al (2015, p. 281): “a implantação de barragens, mesmo que projetadas dentro das técnicas mais modernas e buscando provocar poucos impactos ambientais, produz conflitos de objetivos, especialmente relacionados com a proteção e o aproveitamento dos recursos naturais". Ou seja, é quase inevitável que grandes projetos de geração de energia causem desordem na localidade onde serão implantados.

Há literatura científica consolidada sobre essa assertiva tanto para a Amazônia, como para o Pará. No caso das hidrelétricas de Jirau e Santo Antônio, no município de Porto Velho (RO), para Cavalcante et al. (2011, p. 14):

"A historicidade das transformações ocorridas na área evidencia a emergência de uma nova reestruturação na geografia local pela construção das hidrelétricas no rio Madeira, demanda a necessidade de um plano de gestão territorial que contemple a dinâmica populacional, atividades econômicas e normas de uso (legislações) do território de modo indissociável”. 
Isso evidencia a necessidade de mitigar os conflitos e desordem gerados pelo empreendimento. Para Quaresma (2016), o caso da usina hidrelétrica de Belo Monte é paradigmático, uma vez que a construção esteve regulada pelo Plano de Desenvolvimento Regional do Xingu (PDRSX), e assim mesmo, na prática, a atração de novos investimentos reforçou a aliança entre capital internacional e elites locais, derivando na reprodução de práticas coronelísticas, e reforço à desigualdade espacial e assimetria social.

Nesse cenário, o planejamento para implantação das usinas hidrelétricas deve minimizar o máximo impacto ambiental possível nas áreas de influência direta e indireta dos projetos, especialmente quando os territórios em volta abrigam uma exuberante biodiversidade e um expressivo conjunto de povos indígenas e populações tradicionais que incluem seringueiros, ribeirinhos, castanheiros, entre outros, como a encontrada no Estado do Pará. O debate é na realidade socioambiental, no sentido dado a esse termo pela "ambientalização das lutas sociais" (ACSELRAD, 2010), posto que na Amazônia o respeito ao meio ambiente só é possível com reforço da democracia e de relações sociais menos assimétricas.

Para Oliveira (1992), as populações rurais e indígenas são as mais afetadas pelos grandes projetos hidroelétricos, por causa do seu modo de vida e sua vinculação orgânica com a terra, seu principal meio de produção. No caso do Pará, o padrão espacial das famílias envolvidas em conflitos pela água por causa de hidrelétricas está concentrado no território, com maior proporção na RI Xingu, especialmente em Altamira. Para Dias et al. (1999, p. 283): "a construção de uma barragem pode interromper rodovias, estradas rurais e demais vias de comunicação e até mesmo cidades inteiras, gerando desvantagens econômicas e sociais para os habitantes ribeirinhos e para a região". Nesse cenário negativo à população, é inevitável que surjam movimentos de resistências à construção de hidrelétricas na Amazônia, principalmente em territórios onde há um valor simbólico, histórico e cultural.

Para Souza (1986, p. 32): "há toda uma dimensão histórica e cultural, que se vê seriamente ameaçada, quando não destruída, que não se materializa em terra, habitação, benfeitorias ou hábitos alimentares". Nesse tocante, os grandes projetos hidrelétricos devem impedir o extermínio de grupos étnicos e o aumento do grau de miserabilidade de comunidades tradicionais, rurais e até urbanas.

Não se pode olvidar que esses empreendimentos adiantam um projeto maior do capital internacional, hegemônico no atual momento da globalização que é o controle total dos recursos hídricos do território brasileiro. Para Rodrigues (2010), esse projeto está em fase de implantação 
no Brasil, determinado pelas diretrizes de organismos internacionais como a Organização das Nações Unidades (ONU), o Banco Mundial e o Fundo Monetário Internacional (FMI), embora não plenamente concluído por desajustes com as elites locais que controlam os recursos a nível municipal. Já para Soares et al. (2016a), o rearranjo espacial da economia brasileira na primeira década do século XXI não alterou o papel da Amazônia na divisão territorial do trabalho. Daí se percebe que no atual contexto, os conflitos por água se concentram nas áreas de implantação de grandes projetos hidrelétricos e/ou de mineração.

$\mathrm{Na}$ análise realizada para os municípios paraenses, Altamira se destacou em todos os anos da pesquisa, com variação de 157,1\% entre 2013 e 2016 no número de famílias afetadas e alcançou no ano de 2016, o pico de impacto, quando 8.588 famílias estiveram envolvidas em conflitos (Tabela 4). Em segundo lugar, o limite entre Itaituba e Jacareacanga, na RI Tapajós, teve 4.030 famílias prejudicadas pela restrição à água. Já em terceiro lugar, ainda na RI Tapajós, o limite entre Itaituba e Trairão teve 2.570 famílias envolvidas, seguido pelo município de Senador José Porfírio com 1.423 famílias.

Tabela 4: Quantidade de famílias afetadas em conflitos por água no espaço agrário paraense por municípios ou fronteira (2013-2016)

\begin{tabular}{cccccc}
\hline MUNICÍPIO OU & \multicolumn{5}{c}{ QUANTIDADE DE FAMÍLIAS AFETADAS } \\
\cline { 2 - 7 } FRONTEIRA & 2013 & 2014 & 2015 & 2016 & TOTAL \\
\hline Altamira & 3.340 & 7.289 & 6.721 & 8.588 & 25.938 \\
Senador José Porfírio & 0 & 1 & 1.394 & 28 & 1.423 \\
Barcarena & 0 & 60 & 200 & 260 & 520 \\
Anapu/Senador J. Porf. e Vitória do Xingu & 10 & 0 & 0 & 16 & 26 \\
Itaituba/Trairão & 800 & 800 & 970 & 0 & 2.570 \\
Itaituba/Jacareacanga & 1.400 & 1.400 & 1.230 & 0 & 4.030 \\
Parauapebas & 0 & 0 & 250 & 250 & 500 \\
Itaituba & 0 & 120 & 120 & 0 & 240 \\
Uruará/Altamira/Rurópolis e Medicilândia & 111 & 111 & 0 & 0 & 222 \\
Altamira/São Félix do Xingu & 70 & 76 & 0 & 0 & 146 \\
Vitória do Xingu & 67 & 10 & 0 & 0 & 77 \\
Oriximiná & 0 & 0 & 0 & 40 & 40 \\
São Félix do Xingu & 0 & 0 & 0 & - & - \\
Tucuruí & 0 & 0 & 0 & - & - \\
Trairão & 0 & 0 & 700 & 0 & 700 \\
Ananindeua & 0 & 0 & 300 & 0 & 300 \\
Alenquer & 800 & 0 & 0 & 0 & 800 \\
Acará/Tomé-Açu & 650 & 0 & 0 & 0 & 650 \\
Novo Progresso & 300 & 0 & 0 & 0 & 300 \\
\hline Estado do Pará & 7.548 & 9.867 & 11.885 & 9.182 & 38.482 \\
\hline
\end{tabular}

Fonte: CPT (2013-2016); Elaboração própria 
Indubitavelmente, o município de Altamira é o principal palco de conflitos por água no Estado do Pará, por concentrar 67,4\% ou 25.938 das famílias envolvidas no período analisado, número seis vezes maior do que o segundo lugar, registrado na divisa entre Itaituba e Jacareacanga com $10,5 \%$ ou 4.030 famílias, o que mostra a gravidade dos conflitos naquele município em relação aos demais, como visto abaixo:

Figura 5: Quantidade de famílias envolvidas em conflitos por água no espaço agrário paraense por município ou fronteira (2013-2016)

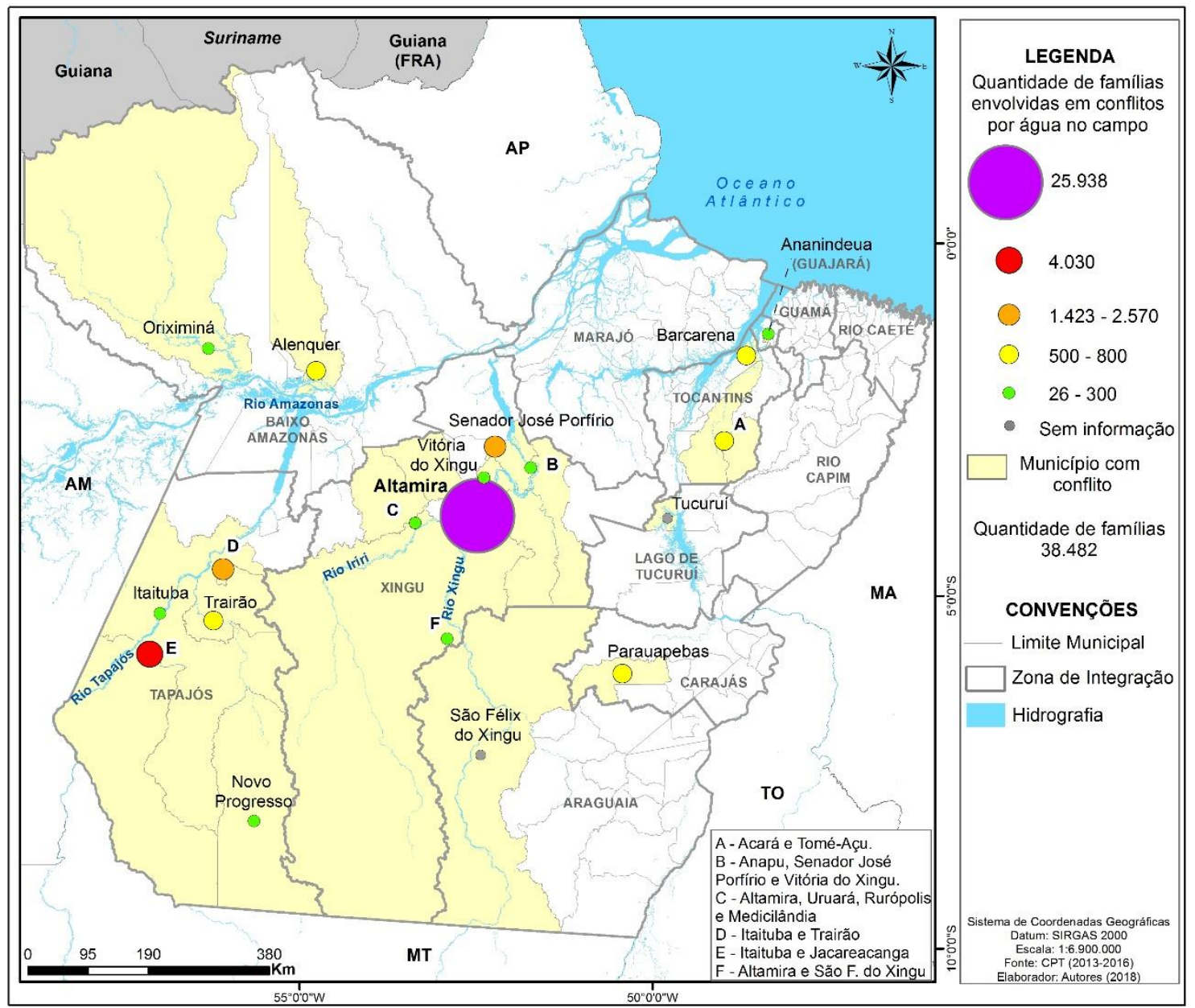

Fonte: CPT (2013-2016); Elaboração própria

No mapa acima, mais uma vez é visível a concentração de famílias afetadas ao longo do rio Xingu, especialmente próximo da área conhecida como Volta Grande do Rio Xingu, que engloba parte dos municípios de Altamira, Senador José Porfírio, Anapu e Vitória do Xingu, onde foram registrados 26 conflitos (44,1\% do Pará) e 27.464 famílias afetadas $(71,4 \%$ do Pará), o que a caracteriza como a principal área por conflito de água no Estado do Pará.

Em segundo plano, destacam-se os conflitos ao longo da calha rio Tapajós, visto na divisa entre Itaituba e Jacareacanga, Itaituba e Trairão, assim como no município de Itaituba, 
totalizando 13 conflitos (22\% do Pará) e 7.840 famílias afetadas (20,4\% do Pará), a maioria relacionado à construção de pequenas centrais hidrelétricas e à futura usina hidrelétrica São Luiz do Tapajós.

Seguindo a discussão traçada por Lobato e Soares (2015), o paradigma da fronteira ainda permite uma interpretação coerente das dinâmicas territoriais presentes na Amazônia brasileira, e particularmente no Estado do Pará. É possível a partir dos dados elencados apontar as RI do Rio Xingu e do Rio Tapajós como a nova fronteira hidroenergética da Amazônia paraense.

Em um terceiro plano os municípios ligados à atividade da mineração, com destaque para Parauapebas (RI Carajás), Oriximiná (RI Baixo Amazonas) e São Félix do Xingu (RI Araguaia). Para Canto et al. (2015), cuja pesquisa tem como base o município de Juruti, a mineração é a atividade econômica mais abissal presente na Amazônia paraense, provocando usos bastante desiguais do território, derivando nos conflitos socioambientais mais graves. Para os autores, a mineração provoca assimetria social, e conflitos pelo uso e pela gestão dos recursos naturais. Esse ponto de vista analítico é corroborado pelas pesquisas empíricas de Soares et al. (2016b), acerca de Paragominas, e de Leite et al. (2018b), para São Miguel do Guamá.

Leite et al. (2016) argumentam que no caso da RI Carajás, os dados mostram que a atividade da mineração reforçou a concentração de renda, e não melhora nos índices sociais, nem propiciou desenvolvimento local. Já Leite et al. (2018a), mostram, na mesma área, que a tecnologia implantada na mineração de grande escala não transborda para aprendizagem e inovação na atividade de mineração social, como nos aglomerados ceramistas. A maior parte da população convive assim apenas com as externalidades negativas da atividade, onde cabe destaque à contaminação de águas superficiais e subterrâneas pelos rejeitos das atividades minerárias.

A RI Tocantins, por sua vez, foi a terceira que mais apresentou conflitos por água no espaço agrário (Tabela 2). Essa RI possui uma diversidade muito grande do ponto de vista da agricultura familiar, com distintos vetores se entrechocando (PIRAUX et al., 2017; QUARESMA et al., 2015). Por um lado, essa RI assiste a expansão sem precedente da monocultura do dendê, alicerçando um modelo de inserção da agricultura familiar junto à plataforma do agronegócio como sua caudatária na década 2003-2013 (CÓRDOBA et al., 2018). Por outro lado, e paradoxalmente, municípios limítrofes entre RI Tocantins e RI Caeté (Acará, Moju, Tailândia, Concórdia do Pará e Tomé-Açu) apresentam uma enorme expansão da produção de mandioca no mesmo período (GUSMÃO et al., 2016). Nessa região, os conflitos por água no espaço agrário estão relacionados à disputa territorial entre esses dois modelos de 
produção, e esses dois vetores distintos, corroborando com a tese da subordinação territorial frente ao projeto hegemônico do agronegócio (OLIVEIRA NETO, 2017).

Em casos mais específicos como no município de Barcarena e de Ananindeua, todos os conflitos foram relacionados ao uso ou preservação dos recursos hídricos, em que alguns rios foram poluídos ou mesmo destruídos, o que desencadeou forte instabilidade entre comunidades rurais e agentes atuantes no território. Em relação a Barcarena, os conflitos envolveram uma empresa mineradora e outra produtora de alimentos. Barcarena é um município que tem concentrado grande parte dos impactos ambientais e dos conflitos socioambientais relacionados à atividade da mineração no Estado do Pará (CARMO et al., 2015).

Para Bordalo et al. (2017), as diversas territorialidades muitas vezes geram conflitos, o que ocasiona o confronto pelo poder, na medida em que os agentes buscam a constante territorialização no que tange aos recursos hídricos. Para os autores, esse o caso dos conflitos hídricos em Barcarena. Nesse tocante, a população rural paraense luta incansavelmente não somente pelo uso dos recursos hídricos, mas também pelo seu território, uma vez que o seu modo de vida está ameaçado por agentes externos, como projetos hidroelétricos, de mineração, entre outros.

De acordo com Roscoche e Vallerius (2014, p. 421): “Tanto a instalação da Usina Hidrelétrica de Belo Monte como a extração de ouro na Volta Grande do Rio Xingu, são contestadas, seja por via judicial, seja pelos movimentos sociais ou organizações não governamentais e outros". A oposição contra a U.H de Belo Monte por atores sociais está intimamente ligada aos impactos socioambientais que este empreendimento tem gerado na região (QUARESMA, 2016).

Entre os possíveis efeitos negativos desta usina, destacam-se: inundação de ilhas e praias próximas de Altamira com consequente perda de atrativos turísticos; prejuízo para a navegação de populações tradicionais como ribeirinhos e indígenas; perda de patrimônio arqueológico, entre outros (ROSCOCHE, VALERIUS 2014; QUARESMA, 2016). Ou seja, podem ocorrer perdas irreparáveis para a história, lazer, modo de vida e outros aspectos para a sociedade.

No caso do município de Ananindeua, apesar da RI Guajará não apresentar a dimensão (apenas 300 famílias atingidas) dos conflitos por água das demais RI paraenses, trata-se do maior aglomerado demográfico do Estado do Pará, e sua dimensão sempre requer atenção. O índice baixo da RI Guajará se deve ao grau de urbanização, e portanto, menor população rural. Costa (2017) comenta que a dimensão dos conflitos hídricos na Região Metropolitana de Belém 
(que corresponde grosso modo à RI Guajará) está muito ligada à questão do abastecimento deficitário de água, sobretudo nas periferias, assim como à questão do saneamento e das enchentes.

Gusmão e Soares (2018) apontam como a produção do espaço geográfico em Belém é desigual, e como o centro de Belém concentra os melhores índices de desenvolvimento, os melhores serviços e equipamentos urbanos, em detrimento da periferia da cidade, onde abundam os aglomerados subnormais, com deficiência de serviços e equipamentos urbanos. Soares et al. (2018) mostram que as inundações periódicas atingem preferencialmente as áreas periféricas de Belém, uma vez que essas áreas possuem cota altimétrica mais baixa, e em virtude da alta especulação imobiliária sobre as áreas mais altas, há manifestação de gentrificação na cidade.

Com isso, percebe-se a dimensão do risco ambiental, não apenas em Barcarena, mas também na RI Guajará que possui um recorte de classe. Tabosa et al. (2016) mostram que o próprio abastecimento de água foi construído de modo a reforçar as assimetrias na produção desigual do espaço em Belém, de modo que as áreas centrais foram privilegiadas no acesso às redes de abastecimento. Isso tudo manifesta que o recorte dos conflitos por água perpassa por dimensões diversas e remetem aos desafios da sociedade assimétrica produzida na Amazônia, e particularmente no Pará.

Uma última ressalva é necessária. Quando comparadas as RI, é inevitável que os grandes empreendimentos hidrelétricos, industriais e metalúrgicos se imponham no que tange aos conflitos por água. Mas os usos da água estão envolvidos em outros tipos de conflitos socioambientais que não necessariamente estão sendo catalogados como tal. Nesse artigo, optou-se pelo uso de dados da CPT pela sua sistematização e organização continuada, mas é mister reconhecer que nas RI Caeté, Guamá e Marajó, que correspondem à zona costeira paraense, apesar do número de conflitos por água catalogados terem sido mínimos, essa área abrange uma série de conflitos históricos relacionados à atividade pesqueira, contrastando modos desiguais da água, que baseiam territorialidades de tempos distintos (SOMBRA et al., 2018).

\section{CONCLUSÕES}

As instalações de usinas hidrelétricas são as principais razões de conflitos no espaço agrário do Estado do Pará, majoritariamente nas Regiões de Integração do Xingu e do Tapajós, as quais constituem a nova fronteira amazônica, do ponto de vista dos recursos hídricos. Pela 
quantidade de conflitos catalogados, e de famílias atingidas, essas devem ser as regiões prioritárias no que tange à gestão de riscos ambientais.

Os dados compilados nesse artigo reforçam a tese de Costa (2017) de que o fato da abundância de recursos hídricos na Amazônia não implica em ausência de problemas ambientais, conflitos e usos competitivos por recursos hídricos na mesma. Muito pelo contrário, o Pará é uma das unidades da federação que mais apresenta conflitos por água e aquela com maior quantidade de famílias envolvidas nessas circunstâncias. Os conflitos por água não constituem qualquer dimensão apartada da sociedade. Ao contrário, estão diretamente relacionados ao modo de produzir o espaço geográfico nessa região, como momento de totalização do projeto capitalista global, em cuja divisão territorial do trabalho cabe à Amazônia o papel de região exportadora de matérias-primas e recursos energéticos.

Fica patente que os órgãos competentes devem adotar medidas mitigadoras na contenção de grandes impactos socioambientais, principalmente para as populações mais vulneráveis e que demonstram resistência diante das obras. Trata-se de processos sociais na escala do mundo em globalização, mas isso não significa que um bom planejamento não possa mitigar alguns dos efeitos mais agudos dos projetos "globalitários" e suas próteses espaciais implantadas na Amazônia.

Por outro lado, espera-se que a sociedade civil possa se organizar de modo apropriado para debater suas necessidades diante das razões alegadas pelo aparato técnico a serviço das grandes companhias e dos grandes empreendimentos, que representam a grande maioria dos atores hegemônicos nos conflitos por água no Estado do Pará, tendo em vista a dimensão da ação local que podem desenvolver. O que não significa ignorar as assimetrias entre forças globais e forças locais, mas considerar como parte de empoderamento da população local para tomar frente desses lugares em globalização que constituem a Amazônia brasileira, onde a dimensão hídrica continua a ser variável chave na interpretação geográfica.

\section{REFERÊNCIAS}

ACSELRAD, H. “Ambientalização das lutas sociais: o caso do movimento por justiça ambiental”. In: Revista Estudos Avançados, São Paulo (SP), v. 24, n. 68, p. 103-119, 2010. BORDALO, C. A. L. "O paradoxo das águas: o caso da Amazônia brasileira". In: Revista Geousp, São Paulo (SP), v. 21, n. 1, p. 120-137, jan;/abr. 2017.

BORDALO, C. A. L.; FERREIRA, D.; SILVA, F. “Conflitos socioambientais pelo uso da água em comunidades ribeirinhas no nordeste paraense: o caso das bacias hidrográficas dos 
Rios Murucupi e Dendê no município de Barcarena-PA”. In: XVII Simpósio Brasileiro de Geografia Física Aplicada, Unicamp, Campinas (SP), 2017.

CAMPOS, V.; FRACALANZA, A. Governança das águas no Brasil: conflitos pela apropriação da água e a busca da integração do consenso. In: Revista Ambiente e Sociedade, Campinas (SP), v.13, n. 2, p.365-382, jul./dez. 2010.

CANTO, O.; ALMEIDA, J.; BASTOS, R. Z.; FARIAS, A.; MENEZES, J. "Mineradora Alcoa: território e conflito no município de Juruti, Pará-Amazônia-Brasil”. In: Revista Geoamazônia, Belém (PA), v. 3, n. 5, p. 63-79, jan./jun. 2015.

CARMO, E. D.; CASTRO, E. R.; PATRÍCIO, J. C. S. "Mineração, neo-extrativismo e conflitos em Barcarena". In: Revista Novos Cadernos NAEA, Belém (PA), v. 18, n. 3, p. 51 71, set./dez. 2015.

CASTRO, C. J. N.; SOARES, D. A. S.; QUARESMA, M. J. N. "Cartografia e ensino de geografia: o uso de mapas temáticos e o processo de ensino-aprendizagem na educação básica". In: Boletim Amazônico de Geografia, Belém (PA), v. 2, n. 3, p. 41-57, jan./jun. 2015.

CAVAlCANTE, M. M. A.; NUNES, D. D.; SILVA, R. G. C.; LOBATO, L. C. H. Políticas territoriais e mobilidade populacional na Amazônia: contribuições sobre a área de influência das hidrelétricas no Rio Madeira, Rondônia/Brasil. In: Confins - Revista Franco-Brasileira de Geografia, São Paulo (SP), n. 11, p. 1-17, 2011.

CÓRDOBA, D.; SELFA, T.; ABRAMS, J. B.; SOMBRA, D. "Family farming, agribusiness and the state: building consent around oil palm expansion in post-neoliberal Brazil". In: Journal of Rural Studies, Amsterdam, v. 57, p. 146-156, 2018.

COSTA, F. E. V. Uma experiência amazônica de gestão dos recursos hídricos: a criação do comitê de bacia hidrográfica do rio Tarumã-Açu, Manaus - AM - Brasil. 132f. Dissertação (Mestrado em Geografia), Universidade Federal do Pará, Belém, 2011.

Gestão dos recursos hídricos na bacia hidrográfica do rio Caeté / Pará-Brasil. 313f. Tese (Doutorado em Geografia), Universidade Estadual Paulista, Presidente Prudente, 2017.

COSTA, F. E. V.; SANTOS, N. S. L.; RODRIGUES, J. I. M. “Apropriação da natureza para fins econômicos e problemáticas ambientais na bacia hidrográfica do Rio Peixe-Boi, na cidade de Peixe-Boi-PA". In: Revista do Instituto Histórico e Geográfico do Pará (IHGP), Belém (PA), v. 2, n. 2, p. 22-34, jul./dez. 2015.

CNRH. CONSELHO NACIONAL DOS RECURSOS HÍDRICOS. Resolução ${ }^{\circ}$ 32, 15/10/2003. Regulamenta a divisão hidrográfica nacional.

CPT. COMISSÃO PASTORAL DA TERRA. Conflitos pela água 2013. Goiânia: CPT, 2013. Disponível em: <https://www.cptnacional.org.br/component/jdownloads/summary/6conflitos-pela-agua/335-conflitos-pela-agua-2013>. Acesso em 03/02/2018. 
Conflitos pela água 2014. Goiânia: CPT, 2014. Disponível em

https://www.cptnacional.org.br/component/jdownloads/summary/6-conflitos-pela-agua/2393conflitos-pela-agua-2014. Acesso em 04/02/2018.

Conflitos pela água 2015. Goiânia: CPT, 2015. Disponível em https://www.cptnacional.org.br/component/jdownloads/summary/6-conflitos-pelaagua/14010-conflitos-pela-agua-2015. Acesso em 06/02/2018.

Conflitos pela água 2016. Goiânia: CPT, 2016. Disponível em https://www.cptnacional.org.br/component/jdownloads/summary/6-conflitos-pelaagua/14041-conflitos-pela-agua-2016. Acesso em 08/02/2018.

DIAS, M. C. O.; PEREIRA, M. C. B.; DIAS, P. L. F.; VIRGÍlLIO, J. F. Manual de impactos ambientais: orientações básicas sobre aspectos ambientais de atividades produtivas. Fortaleza: Banco do Nordeste, 1999.

ELETROBRÁS, CENTRAIS ELÉTRICAS BRASILEIRAS. Plano 2010: Relatório geral. Rio de Janeiro: ELETROBRÁS, 1987

GIRARDI, E. Manual de utilização do programa Philcarto: versão 4x para Windows. São Paulo: UNESP, 2007.

GUSMÃO, L. H. A.; HOMMA, A. K. O.; WATRIN, O. S. “Análise cartográfica da concentração do cultivo de mandioca no estado do Pará, Amazônia brasileira”. In: Revista Geografia, Ensino e Pesquisa, Santa Maria (RS), v. 20, n. 3, p. 51-62, 2016.

GUSMÃO, L. H. A.; SOARES, D. A. S. "Produção desigual do espaço: o processo de verticalização em Belém (PA)”. In: Revista Contribuciones a las Ciencias Sociales, Málaga, v. 39, p. 1-17, jan. 2018.

IBGE, INSTITUTO BRASILEIRO DE GEOGRAFIA E ESTATÍSTICA. Censo Demográfico de 2010. Disponível em: 〈https://cidades.ibge.gov.br/brasil/pa/panorama〉. Acesso em 12/03/2018.

JUCHEM, P. A. Técnicas para avaliação de impacto ambiental e elaboração de estudos de impacto ambiental de empreendimentos selecionados: projetos de aproveitamento hidrelétrico. Curitiba: IAP/GTZ, 1992.

LEITE, A. S.; SOARES, D. A. S.; TRINDADE, J. R. B. "Renda mineral e grande capital na Amazônia: a exploração das minas de Carajás pela Companhia Vale". In: Revista Leituras de Economia Política, Campinas (SP), v. 24, p. 55-78, jan./dez. 2016.

LEITE, A. S.; FERNANDES, D. A.; SOARES, D. A. S.; KATO, E. S. “Aprendizagem territorial, cooperação e inovação em espaços rurais: o caso da aglomeração ceramista de Eldorado dos Carajás (Pará/Brasil)". In: Revista Caribeña de Ciencias Sociales, Málaga, v. 7, p. 1-23, mar. 2018a.

LEITE, A.; SOMBRA D.; SOMBRA, A. "Desenvolvimento local e gestão de recursos naturais em São Miguel do Guamá (Pará-Brasil): aprendizagem territorial, cooperação e 
inovação no arranjo produtivo local de indústrias ceramistas". In: Revista Observatorio de la Economía Latinoamericana, Málaga, v. 14, p. 1-41, abr. 2018b.

LOBATO, M. M.; SOARES, D. A. S. "Fronteira na geografia: proposições para uma reflexão". In: Boletim Amazônico de Geografia, Belém (PA), v. 2, n. 3, p. 175-193, jan./jun. 2015.

MARTINELLI, M. Mapas da Geografia e Cartografia Temática. $6^{\text {a }}$ ed. São Paulo: Contexto, 2011.

\section{MMA, MINISTÉRIO DO MEIO AMBIENTE. Caderno da Região Hidrográfica} Amazônica. Brasília: MMA, 2006.

OLIVEIRA, N. M. "Análise das Audiências Públicas no Estado de Paraná”. In: Seminário sobre Avaliação de Impacto Ambiental em Áreas Urbanas, Secretaria de Estado de Meio Ambiente, Curitiba (PR), 1992, p. 56-64.

OLIVEIRA NETO, A. C. Territórios subordinados: análise da política de desenvolvimento territorial a partir da produção de óleo de palma pela Agropalma em assentamentos de reforma agrária no Pará. 338f. Tese (Doutorado em Geografia). Universidade Estadual Paulista, Presidente Prudente, 2017.

PARÁ. GOVERNO DO ESTADO. Decreto-Lei no 1.066, de 19 de junho de 2008. Dispõe sobre a regionalização oficial do Estado do Pará e dá outras providências.

PIRAUX, M.; SOMBRA, D.; SIMÕES, A. V. “A diversidade socioespacial do território do Baixo Tocantins e impactos na agricultura familiar". In: SIMÕES, A.; BENASSULY, M. (Org.). Na várzea e na terra firme: transformações socioambientais e reinvenções camponesas. Belém: NUMA/UFPA, 2017, p. 77-114.

QUARESMA, M. J. N. Usina hidrelétrica de Belo Monte: da modernização do território à reconfiguração das escalas de poder. 138f. Dissertação (Mestrado em Geografia), Universidade Federal Fluminense, Niterói, 2016.

QUARESMA, M.; SOMBRA, D.; LEITE, A.; CASTRO, C. "Periodização econômica de Abaetetuba (PA) a partir de sua configuração espacial". In: Revista PerCursos, Florianópolis (SC), v. 16, n. 32, p. 143-168, set./dez. 2015.

RODRIGUES, E. B. Território e soberania na globalização: Amazônia, jardim de águas sedento. 406f. Tese (Doutorado em Geografia), Universidade de São Paulo, São Paulo, 2010. ROSCOCHE, F. L.; VALLERIUS, M, D. "Os impactos da usina hidrelétrica de Belo Monte nos atrativos turísticos da região do Xingu". In: Revista Eletrônica de Administração e Turismo, Pelotas (RS), v. 5, n. 3, p. 414-430, jul./dez. 2014.

SOARES, A. A. S.; CARVALHO, A. C.; SOARES, D. A. S.; BASTOS, R. Z. "Fundamentos para a gestão das inundações periódicas nas planícies de Belém (Pará-Brasil) com vistas ao seu desenvolvimento local". In: Revista Contribuciones a las Ciencias Sociales, Málaga, v. 39, p. 37-56, jan. 2018. 
SOARES, D. A. S.; LEITE, A. S.; LOBATO, M. M. "Estado e capital: subsídios para a compreensão analítica do protagonismo do Estado brasileiro no rearranjo espacial da América do Sul”. In: Revista Geoamazônia, Belém (PA), v. 4, n. 7, p. 47-77, jan./jun. 2016a.

SOARES, D. A. S.; LEITE, A. S.; LOBATO, M. M.; CASTRO, C. J. N. "Usos do território em Paragominas: espaço geográfico e classes sociais”. In: Revista Tocantinense de Geografia, Araguaína (TO), v. 5, n. 8, p. 1-29, jul./dez. 2016 b.

SOMBRA, D.; MOTA, G. S.; LEITE, A. S.; CASTRO, C. J. N. “A reterritorialização pesqueira no estado do Pará: reprodução contraditória das relações capitalistas”. In: Revista de Geografia (Recife), Recife (PE), v.35, n. 2, p. 243-267, 2018.

SOUZA, A. T. Os trabalhadores na Amazônia Paraense e as grandes barragens. In: As hidrelétricas do Xingu e os Povos Indígenas. São Paulo: Comissão Pró-Índio, 1986.

TABOSA, R.; SOMBRA, D.; LEITE, A.; CASTRO, C. "Revisão histórico-geográfica da gestão pública sobre o abastecimento hídrico de Belém-PA”. In: InterEspaço - Revista de Geografia e Interdisciplinaridade, Grajaú (MA), v. 2, n. 5, p. 196-220, jan./abr. 2016.

Recebido em Maio de 2020

Aprovado em Julho de 2020

Publicado em Fevereiro de 2021 